\title{
On the Aortic Nerve of the Tortoise.
}

\author{
By \\ Kenzo Hasimoto and Shuzi Hirohata. \\ (橋本捲藏) (度幡修二) \\ (From the Physiological Laboratory of Prof. Y. Satake, \\ Tohoku Imperial University, Sendai.)
}

The aortic nerve of the tortoise was first systematically, particularly anatomically, studied by Kazem-Beck ${ }^{122}$ half a century ago, and thereafter apparently disregarded. According to his physiological researches, few in number, the depressor seems to contain two kinds of afferent nerves, depressor and pressor ; judging from his description, it seems desirable to make certain upon this point.

There are the following statements rê the depressor nerve in the description of $\mathrm{Mill}^{3}$ ) on the experiment on a sea turtle (testudo cephalo), made in conjunction with Kronecker; "On the left side...... stimulation of a very fine nerve-branch of the Vagus caused standstill, as an after-action (Nachwirkung) very marked increase in the pluse which lasted several minutes. 'This was arrested by stimulation of the Vagus. Shortly afterwards stimulation of this nerve had no influence either in retarding or accelerating the heart's action. This nerve was traced to a ganglion very high up on the Vagus and seemed to run without giving off branches into the thoracic cavity, but having broken off low down could be accurately traced throughout. It remainded one very forcibly of the Depressor of the rabbit."

Of the testudo graeca Gaskell and Gado w's ${ }^{4)}$ description was: Besides these cardiac nerves another fine nerve is apparently given off from the cervical sympathetic to pass directly to the heart. This nerve is in very close connection with the sympathetic but can be traced as a separate nerve to the occipital region, where it leaves the sympathetic and joins the G. jugulare of the vagus. This nerve would correspond therefore in its course to the N. depressor in mammals. ${ }^{4)}$
1) Ka zem-Beck, Ctrlbl. f. med. Wiss., 1885, 23 year, 482.
2) Ibid., Arch. f. Anat. u. Physiol., Anat. Abt, 1888, 338 ff.
3) Mills, J. of Physiol., 1884, 5, 360.
4) Gaskell and Gadow, Ibid., 367. 
In the next year, Mills $\mathrm{s}^{5)}$ put the matter to the test and pronounced that for this species of tortoise there is no physiological depressor, the blood pressure experiment being carried on the slider terrapin. He then wrote: Every small nerve with the slightest resemblance to such an one as was likely to possess this character, including a fine nerve exactly such as himself, and Gaskell and Gad ow referred to, have taken for a depressor, was examined.

In a preliminary report, $\mathrm{Ka}$ z e $\mathrm{m}-\mathrm{B}$ e $\mathrm{ck}^{1)}$ presented the data observed on the testudo europea. He detected a thin nerve which springs off often with a single root from the g. jug. vagi or from the truncus laryngo-oesphageus, or with two roots from the jugular ganglion and the oesophageal branch. It runs between the vago-sympathetic nerve and the carotid, and, joining with a nerve fibre branching from the ganglion above the recurrent nerve, ends in the muscle of the heart ventricle. On stimulating the central end of the left side nerve he was once able to observe a stand-still of the heart beat for 20 seconds. In the majority of cases only a retardation was noted, while in some cases only the negative result was yielded. Stimulation of the periphery end caused, on the contrary, strengthning of the heart contraction.

A few year later") he presented a full account of his extensive investigations. 61 emys caspica was anatomically examined; the depressor nerve was bilaterally discovered. 8 exemplars had two roots, one thick, long root from the jugular ganglion of the vagus and another from the laryngo-pharyngeal trunk or from its branch, the pharyngeal nerve. Among them 5 individuals had the two roots only on left side. All the other individuals had only one root, commonly from the jugular ganglion of the vagus, seldom from the laryngo-pharyngeal nerve. Excepting a few cases, the depressor runs to the heart independently, in parallel to the vago-sympathetic or the sympathetic, when it is isolated from the vagus. At the aortic arc the depressor splits into two branches, and one of them ruus along to the aorta and finally enters to the muscle of the bulbus and the other thick branch runs towards the heart and partly to the arteries after joining usually with a branch from the ganglion trunci vagi. The left depressor goes to the ventral sides of the arteries, and the right to the dorsal.

Two testudo ibera were also examined, where the depressor was found to possess only one root, either from the jugular ganglion of the vugus or the laryngo-pharyngeal trunk.

He was not able, he said, to carry out the physiological study sufficiently because of insufficiency of material. On stimulating the central end of the depressor the blood pressure was rather elevated than lowered. A similar result was obtained with the nerve coming from the gangl. trunci vagi.

Stimulation of the central end of the depressor caused sometimes a standstill of the heart beat for a few seconds, but often the heart contraction became slower or only weaker.

These actions were nullified by sectioning the vagi and the sympathetic.

The anatomical sesearches of $\mathrm{Kaz} \mathrm{em}-\mathrm{Beck}$ of the depressor thus are ad-

5) Mills, J. of Physiol., 1885, 6, 269 f. 

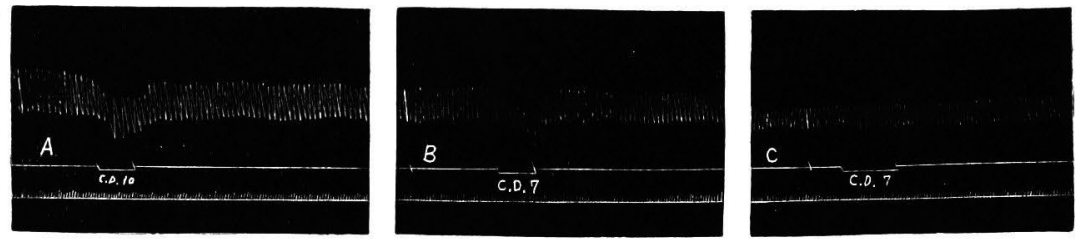

Showing effects of stimulating the aortic nerves (Reduced to $\frac{1}{2}$ ).

Clemmys japonica ô $14 \mathrm{cms}$. long. Room temperature $17^{\circ} \mathrm{C}$. 25. X. 1934. Upper curve: Arterial pressure by $\mathrm{Hg}$ - manometer; middle line: Its zero line with remarking stimulation; lower line: Time in second. (A) Stimulating the right nerve, (B) the left, and $(C)$ the left after double vagotomy.

mirably thorough, but his physiological investigations are seemingly unsatisfactory as he confessed himself.

We have had a few opportunities of investigating this question in Japanese tortoise, clemmys japonica (Temminck et Schlegel).

We found in each case of five individuals in all, a nerve strand branching from the ganglion trunci vagi and running towards the heart, so that finally it was followed between the aorta and the pulmonary artery, accordingly on the ventral wall of the aorta on the left side and on the dorsal on the right. Arterial blood pressure was recorded by means of a mercury manometer with the inner diameter of 2 millimeters connected with a glass cannula inserted in to the left pulmonary artery, the connective tube being filled with 5 per cent sodium citrate solution. No narcosis was used.

This nerve was stimulated, with reflex blood pressure fall and slow pulse. Kazem-Beck observed apparently a great rise of the blood pressure rather than a fall on stimulating this nerve strand. He noted also the heart beating slower or only weaker.

In the present experiment the stimulation was continued for 12 seconds to 40 seconds, the pulse rate was diminished by $6-24$ beats a minute, and the mean arterial blood pressure fell by $1-8 \mathrm{mms}$. Hg. If the magnitude of reduction be compared to the initial value, it is about 15 to $30 \%$ and 8 to $50 \%$ (mostly over $30 \%$ ) respectively. In nearly all cases the reduction and the fall were greatest during the stimulation ; only in one case were they so just after discontinuing the stimulation.

In some cases the height of the heart contraction became smaller simultaneously.

The vagus , trunk was then unilaterally cut under the ganglion trunci vagi, and the aortic nerve, mostly of the ipsilateral side, was 
again stimulated for 20 to 30 seconds. In nearly all cases the heart rate became slower and the blood pressure fell, the scale being $2-24$ beats per minute and $2-7 \mathrm{mms}$. $\mathrm{Hg}$. or $5-65 \%$ (mostly $25 \%$ ) and 15 to $30 \%$ of the initial value. In one case the contraction of heart became evidently smaller. In one case where the arterial pressure fell but the heart rate remained unaltered, the height of contraction was registered considerably diminished.

At last the remaining vagus was sectioned under the ganglion trunci, then no alteration was seen in the pressure and the pulse rate on stimulating the aortic nerve. This finding is similar with that of $\mathrm{Kazem-Beck}$; he sectioned the sympathetics in addition to the vagi. At any rate it is remarkable in this species of animal that mere sectioning the efferent cardiac nerves abolishes the effect of stimulating the aortic nerve at all, that is not only the influence upon the heart beat, but also that upon the arterial blood pressure, contrary to mammalians.

Simply epitomized: In a tortoise, clemmys japonica, we were able to see always a reduction of the heart beat, in frequency and strength as well, and a fall of the arterial blood pressure on stimulating a nerve strand (the aortic nerve or the depressor) coming from the ganglion trunci vagi and running towards the heart. These effects were abolished by double vagotomy under the ganglion. 